\title{
Primary Care's Historic Role in Vaccination and Potential Role in COVID-19 Immunization Programs
}

\author{
Elizabeth Wilkinson ${ }^{1}$ \\ Anuradha Jetty, MPH \\ Stephen Petterson, $\mathrm{PbD}^{1}$ \\ Yalda Jabbarpour, $M D^{1}$ \\ Jobn M. Westfall, MD, MPH \\ ${ }^{1}$ The Robert Graham Center for Policy \\ Studies in Family Medicine and Primary \\ Care, Washington, DC
}

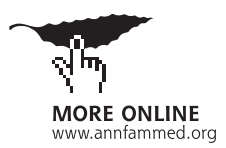

Conflicts of interest: authors report none.

\author{
CORRESPONDING AUTHOR \\ John M. Westfall \\ The Robert Graham Center \\ for Policy Studies in Family Medi- \\ cine and Primary Care \\ 1133 Connecticut Avenue NW \\ Washington, DC, 20036 \\ JWestfall@aafp.org
}

\begin{abstract}
PURPOSE Coronavirus disease 2019 (COVID-19) pandemic recovery will require a broad and coordinated effort for infection testing, immunity determination, and vaccination. With the advent of several COVID-19 vaccines, the dissemination and delivery of COVID-19 immunization across the nation is of concern. Previous immunization delivery patterns may reveal important components of a comprehensive and sustainable effort to immunize everyone in the nation.
\end{abstract}

METHODS The delivery of vaccinations were enumerated by provider type using 2017 Medicare Part B Fee-For-Service data and the 2013-2017 Medical Expenditure Panel Survey. The delivery of these services was examined at the service, physician, and visit level.

RESULTS In 2017 Medicare Part B Fee-For-Service, primary care physicians provided the largest share of services for vaccinations (46\%), followed closely by mass immunizers (45\%), then nurse practitioners/physician assistants (NP/PAs) $(5 \%)$. The Medical Expenditure Panel Survey showed that primary care physicians provided most clinical visits for vaccination ( $54 \%$ of all visits).

CONCLUSIONS Primary care physicians have played a crucial role in delivery of vaccinations to the US population, including the elderly, between 2012-2017. These findings indicate primary care practices may be a crucial element of vaccine counseling and delivery in the upcoming COVID-19 recovery and immunization efforts in the United States.

Ann Fam Med 2021;19:351-355. https://doi.org/10.1370/afm.2679.

Annals "Online First" article.

\section{INTRODUCTION}

W

hile the coronavirus disease 2019 (COVID-19) pandemic continues to wax and wane throughout the country, efforts must combine the best pandemic response with preparation for pandemic recovery. Experts have called for widespread testing, contact tracing, and case isolation as preconditions for safely reopening schools, lifting activity restrictions, and preventing future COVID-19 resurgence. ${ }^{1,2}$ Scientific knowledge of the immunity conferred by antibodies developed by infection with COVID-19 is evolving, but public health experts agree that herd immunity from infection is an unreasonable approach to tackling the pandemic. ${ }^{3-5}$ The arrival of safe and effective vaccines brings hope and may alleviate some of the complexities related to testing and treatment. ${ }^{6-8}$

An important step toward recovery from COVID-19 is the mass distribution of a vaccine. ${ }^{9-12}$ While much attention has been on the development and manufacturing of a novel severe acute respiratory syndrome coronavirus 2 (SARS-CoV-2) vaccine, it is now clear that the distribution and delivery also require careful planning. ${ }^{13}$ Many reports highlight the role of large chain pharmacies to deliver the COVID-19 vaccine. Complex and expensive shipping and storage requirements of the first approved vaccine require detailed planning. Additional vaccines entering the market may eliminate many of these more complex storage requirements. Access 
to the vaccination in large population centers as well as remote rural areas will require use of current and novel networks to reach adequate herd immunity levels.

Even if the United States is able to appropriately deliver the COVID-19 vaccine to all communities, vaccine hesitancy may slow herd immunity. A recent Kaiser Family Foundation survey found that over a quarter of adults in the United States are hesitant to get the COVID-19 vaccine, and this proportion is much higher in certain populations and geographies. ${ }^{14}$ Without appropriate counseling about the vaccine, the potential for recovery is hampered. Surveys have shown that the most trusted source of information on the COVID-19 and other vaccines is a patient's own doctor or health care provider. ${ }^{15}$ But no studies, to our knowledge, have quantified where patients have historically received their vaccines.

This study examines the role of primary care physicians and other providers in delivering vaccinations in the United States. We used 2 main data sets to create an in-depth analysis of services delivered to the Medicare Part B Fee-For-Service (FFS) beneficiary population, followed by analysis of the Medical Expenditure Panel Survey to determine delivery patterns for immunizations among all age groups. The combination of these 2 data sets provides a robust analysis of a representative sample of adults of all ages living in the United States. Historic immunization delivery patterns may shed light on provider capacity for rapid deployment of COVID-19 vaccine counseling and delivery.

\section{METHODS}

\section{Medicare Fee-For-Service}

This study uses Centers for Medicare and Medicaid Services (CMS) 2017 Medicare Provider Utilization and Payment Data: Physician and Other Supplier Public Use File (PUF) and CMS National Plan and Provider Enumeration System (NPPES) August 2017 Quarter 3 Update. The Physician and Other Supplier PUF includes services provided to beneficiaries enrolled in Medicare Part B FFS in 2017 at the provider level. We linked the data files using National Provider Identifier (NPI) and geocoded providers' addresses at the county level using NPPES. We calculated vaccination services by provider type and county. We categorized primary care physicians (PCPs) in the Medicare PUF using the standard method that includes family practice, general practice, geriatric medicine, or internal medicine. "Mass immunizers" include drugstore and grocery chains as well as community pharmacies and were identified using the provider terms of centralized flu, mass immunizer roster biller, pharmacy, or public health or welfare agency. The Medicare PUF does not differentiate internal medicine physicians that are specialists from those that practice general internal medicine. The Medicare PUF includes non-physician provider types of physician assistant (PA), nurse practitioner (NP), and certified clinical nurse specialist, but does not provide specialty of PAs or NPs.

We used Healthcare Common Procedure Coding System (HCPCS) code descriptions to identify services in the Medicare PUF. To be included as a vaccination service, the description must have contained "vaccine" or "vaccination" and not have contained "detection" (Supplemental Table 1, available at https:// www.AnnFamMed.org/lookup/suppl/doi:10.1370/ afm.2679/-/DC1).

\section{Medical Expenditure Panel Survey}

We merged medical conditions, office-based, outpatient and consolidated files from the Medical Expenditure Panel Survey (MEPS) to enumerate services delivered in office-based and outpatient visits in 2013 through 2017. We used multiple years to assure adequate sample size. MEPS provides nationally representative estimates of health care services and expenditures for adults of all ages. We used questions related to reasons for visit from the office-based and outpatient files to identify visits for vaccination (Supplemental Table 2, available at https://www.AnnFamMed. org/lookup/suppl/doi:10.1370/afm.2679/-/DC1). We included physicians with specialties of family medicine, internal medicine, pediatrics, and geriatrics in the PCP category in MEPS. We calculated the number and proportion of visits for vaccinations seen by PCPs, NP/PAs and other non-physician providers using survey weights averaged over the 5 years pooled from 2013-2017 which result in a nationally representative sample for 1 year.

A Medicare "service" is a unique billing code, and a clinical encounter might include multiple "services." While MEPS uses different terminology for clinical care (visit, encounter, service), we used the term "visit" to represent any clinical encounter that included a vaccination. For MEPS, these visits might include multiple services, but each visit is only counted once. We used Stata version 16.0 (Stata Corp) for analysis. Percentages are rounded to the nearest whole number.

\section{RESULTS}

\section{Medicare Fee-For-Service}

There were over 2.4 billion services included in the 2017 Medicare Physicians and Other Supplier PUF including nearly 34.3 million vaccinations (Table 1 ). There were 1,032,911 unique clinical providers of 
Table 1. Medicare Part B Fee-For-Service Billable Services and Vaccinations by Provider Type, 2017

\begin{tabular}{|c|c|c|c|c|c|c|c|c|}
\hline \multirow[b]{2}{*}{ Provider Type } & \multicolumn{2}{|c|}{$\begin{array}{l}\text { Total Number } \\
\text { of Services }\end{array}$} & \multicolumn{2}{|c|}{$\begin{array}{l}\text { Unique } \\
\text { Providers }\end{array}$} & \multicolumn{2}{|c|}{ Vaccination } & \multicolumn{2}{|c|}{$\begin{array}{c}\text { Unique Vaccine } \\
\text { Providers }\end{array}$} \\
\hline & $\mathrm{n}$ & $\%$ & $\mathbf{n}$ & $\%$ & $\mathbf{n}$ & $\%$ & $\mathbf{n}$ & $\%$ \\
\hline Mass immunizer & $15,476,697$ & 0.6 & 40,246 & 3.9 & $15,474,448$ & 45.2 & 40,242 & 26.7 \\
\hline Centralized flu & $6,382,129$ & 0.3 & 9,793 & 1.0 & $6,382,129$ & 18.6 & 9,793 & 6.5 \\
\hline Mass immunizer roster biller & $8,979,771$ & 0.4 & 30,144 & 2.9 & $8,978,511$ & 26.2 & 30,142 & 20.0 \\
\hline Pharmacy & 7,484 & 0.0 & 29 & 0.0 & 6,564 & 0.0 & 27 & 0.0 \\
\hline Public health or welfare agency & 107,313 & 0.0 & 280 & 0.0 & 107,244 & 0.3 & 280 & 0.2 \\
\hline Primary care physician & $315,693,224$ & 13.1 & 183,475 & 17.8 & $15,834,619$ & 46.2 & 77,627 & 51.4 \\
\hline Family practice & $122,477,653$ & 5.1 & 81,809 & 7.9 & $7,704,970$ & 22.5 & 41,777 & 27.7 \\
\hline General practice & $6,989,241$ & 0.3 & 4,943 & 0.5 & 198,196 & 0.6 & 1,264 & 0.8 \\
\hline Geriatric medicine & $2,442,902$ & 0.1 & 1,811 & 0.2 & 87,031 & 0.3 & 478 & 0.3 \\
\hline Internal medicine & $183,783,428$ & 7.6 & 94,912 & 9.2 & $7,844,422$ & 22.9 & 34,108 & 22.6 \\
\hline NP/PA/CCNS & $102,676,780$ & 4.3 & 171,180 & 16.6 & $1,592,519$ & 4.7 & 20,861 & 13.8 \\
\hline Certified clinical nurse specialist & 949,837 & 0.0 & 1,979 & 0.2 & 3,897 & 0.0 & 40 & 0.0 \\
\hline Nurse practitioner & $63,649,600$ & 2.6 & 104,098 & 10.1 & $1,198,546$ & 3.5 & 15,391 & 10.2 \\
\hline Physician assistant & $38,077,343$ & 1.6 & 65,103 & 6.3 & 390,076 & 1.1 & 5,430 & 3.6 \\
\hline Clinical laboratory & $314,641,419$ & 13.1 & 2,838 & 0.3 & 126 & 0.0 & 3 & 0.0 \\
\hline Other & $1,662,710,608$ & 69.0 & 635,172 & 61.5 & $1,364,870$ & 4.0 & 12,161 & 8.1 \\
\hline Total & $2,411,198,729$ & 100 & $1,032,911$ & 100 & $34,266,581$ & 100 & 150,894 & 100 \\
\hline
\end{tabular}

which 150,894 (15\%) delivered vaccinations. Overall, PCPs provided the most vaccinations $(46 \%)$, followed closely by mass immunizers (45\%), then NP/PAs (5\%).

An examination of vaccinations at the county level showed that PCPs administered between $25 \%$ to $50 \%$ of vaccinations in the majority of counties in Medicare Part B FFS in 2017. Additionally, there were clusters of counties that had over $50 \%$ of vaccinations provided by PCPs throughout states such as Louisiana, Pennsylvania, and Massachusetts (Supplemental Figure 1).

\section{Medical Expenditure Panel Survey}

There were an average 69.7 million vaccination visits in office-based settings in the United States per year, according to the 2013-2017 MEPS (Table 2). The majority of visits for vaccinations were with PCPs (53.6\%).

\section{DISCUSSION}

Historically, primary care practice has played an important role in vaccine delivery. Because many patients have received their vaccines from their primary care practice, these same practices may play a crucial role in the COVID-19 immunization dissemination and delivery. Whether primary care physicians provide the vaccine, or only provide immunization counseling, their role may help assure successful delivery of the COVID-19 vaccines to communities across the nation, including rural and remote communities. In addition to physically administering vaccinations, PCPs can provide clinical and personal support to enable patients to understand their current COVID-19 immunologic status, how that may impact their vaccine decisions, and to counter vaccine hesitancy and misinformation. ${ }^{16}$ Manufacturers already deliver vaccines and Medicare has individual provider and practice billing information for primary care practices that provide vaccines, therefore, a distribution list

Table 2. Vaccination Visits by Provider Type in
Medical Expenditure Panel Survey, 2013-2017

\begin{tabular}{lc}
\hline Provider Type & $\begin{array}{c}\text { Vaccination Visits } \\
\text { No., Weighted (\%) }\end{array}$ \\
\hline Primary care physicians & $37,332,602(53.6)$ \\
Family medicine & $13,618,734(19.5)$ \\
Internal medicine & $2,971,356(4.3)$ \\
Pediatrics & $20,664,522(29.6)$ \\
Geriatrics & $77,990(0.1)$ \\
NP/PA & $15,584,875(22.4)$ \\
Non-primary care physician & $7,859,141(11.3)$ \\
Other nonphysician & $8,934,141(12.8)$ \\
Total & $67,299,316(100)$ \\
\hline NP $=$ nurse practitioner; PA = physician assistant. \\
Note: Source: Medical Expenditure Panel Survey, 2013-2017.
\end{tabular}


is ready-made. Using the current vaccine delivery in primary care may greatly improve COVID-19 vaccine distribution.

Given the political nature of the COVID-19 pandemic, including the vaccine development and approval process, there is a high level of distrust in the COVID19 vaccine. ${ }^{17}$ The new vaccines may face more vaccine hesitancy, misinformation, and refusal than other vaccines. Primary care physicians are often considered a trusted source of medical information. And, based on the historic immunization data, are evidently a trusted source for vaccine information. In addition to delivering the actual vaccine, primary care practices may play an even more important role in vaccine counseling, building local community trust, and serving as a source of scientific knowledge about the COVID-19 vaccine.

The COVID-19 pandemic has not affected all populations equally - the Medicare Fee-For-Service (FFS) beneficiary population, comprised of over 40 million people who are mostly aged 65 years and over, is disproportionately at risk for complication and death due to COVID-19. ${ }^{17,18}$ Delivering vaccinations to this older population is essential for mitigating the most devastating consequences of the virus. Closer examination of the provision of these services by patient race and ethnicity, while beyond the scope of this paper, is also critical, as the COVID-19 pandemic has disproportionately affected Black, Latino, and Indigenous American persons, who also experience lower rates of vaccination and higher likelihoods of concurrent COVID-19 risk factors. ${ }^{19-23}$

The Medicare PUF used in this study does not allow for the identification of the originating provider who may have referred to a mass immunizer or other facility for vaccination. Additionally, the Medicare PUF limits aggregation of services to providers with 10 or more beneficiaries per HCPCS code. Further, the use of county-level data does not account for beneficiaries who traveled across counties to receive a service.

The Medical Expenditure Panel Survey is based on self-reported patient data and is subject to recall bias however, one-third of the sample is validated using a sample of providers and delivery sites. Its non-institutionalized civilian population sample may not reflect the vaccination rates of the entire US population. MEPS is widely used and considered a reliable source for health services research.

None of the data sets allow for differentiating specialist internal medicine from general internal medicine, nor do they provide the level of detail necessary to determine specialty of NP/PAs or if NP/PAs may have been ordering immunizations but billing under a physician code. In addition, NPs could not be distinguished from nurses since MEPS groups these clinicians into a single category. Therefore, these data may overestimate the contribution of vaccination by general internal medicine and underestimate the contribution of vaccination by NP/PAs.

Primary care physicians deliver preventive care as well as address acute and chronic medical needs. They are equipped to provide clinical guidance to help patients interpret results from COVID-19 testing and immunity determinations and answer vaccine questions. Given its historic role in immunization counseling and vaccine delivery, primary care, in concert with public health agencies and community health organizations, is essential for immediate and sustainable population health efforts to address COVID-19 recovery.

To read or post commentaries in response to this article, go to https://www.AnnFamMed.org/content/19/4/351/tab-e-letters.

Key words: vaccination; public health; primary care; Medicare; COVID-19

Submitted August 27, 2020; submitted, revised, January 22, 2021; accepted February 1, 2020.

Supplemental materials: Available at https://www.AnnFamMed. org/lookup/suppl/doi:10.1370/afm.2679/-/DC1.

\section{References}

1. Centers for Disease Control and Prevention. Implementation of mitigation strategies for communities with local COVID-19 transmission. Published 2020. https://www.cdc.gov/coronavirus/2019-ncov/ downloads/community-mitigation-strategy.pdf

2. Begley S. Many states short of Covid-19 testing levels needed for reopening. STAT. Published Apr 27, 2020. Accessed Jun 10, 2020. https://www.statnews.com/2020/04/27/coronavirus-many-statesshort-of-testing-levels-needed-for-safe-reopening/

3. Zhao J, Yuan Q, Wang $H$, et al. Antibody responses to SARS-CoV-2 in patients with novel coronavirus disease 2019. Clin Infect Dis. 2020;71(16):2027-2034. https://doi.org/10.1093/cid/ciaa344

4. Dan JM, Mateus J, Kato Y, et al. Immunological memory to SARSCoV-2 assessed for up to 8 months after infection. Science. 2021: eabf4063. https://doi.org/10.1126/science.abf4063.

5. World Health Organization. Coronavirus disease (COVID-19): herd immunity, lockdowns and COVID-19. Published Dec 2020. Accessed Jan 21, 2021. https://www.who.int/news-room/q-a-detail/ herd-immunity-lockdowns-and-covid-19

6. Cassidy CA, Matthew P, Dearen J, Forster NAP. Most states fall short of coronavirus testing thresholds. AP NEWS. Published May 2, 2020. Accessed Jun 10, 2020. https://apnews.com/64a594728f6e36480ee 38cc1502436cc

7. Sutton D, Fuchs K, D'Alton M, Goffman D. Universal screening for SARS-CoV-2 in women admitted for delivery. N Engl J Med. 2020; 382(22):2163-2164. https://doi.org/10.1056/NEJMc2009316

8. Office of the Assistant Secretary for Health. SARS-CoV-2 (COVID19) fact sheet. Published May 22, 2020. Accessed Jun 10, 2020. https://www.cdc.gov/coronavirus/2019-ncov/downloads/OASH-nasalspecimen-collection-fact-sheet.pdf

9. Lurie N, Saville M, Hatchett R, Halton J. Developing Covid-19 vaccines at pandemic speed. N Engl J Med. 2020;382(21):1969-1973. https://doi.org/10.1056/NEJMp2005630

10. Soucheray S. Fauci: Vaccine at least year away, as COVID-19 death toll rises to 9 in Seattle. Center for Infectious Disease Research and Policy. Published Mar 3, 2020. Accessed Jun 10, 2020. https://www.cidrap.umn.edu/news-perspective/2020/03/ fauci-vaccine-least-year-away-covid-19-death-toll-rises-9-seattle 
11. Thanh Le T, Andreadakis Z, Kumar A, et al. The COVID-19 vaccine development landscape. Nat Rev Drug Discov. 2020;19(5):305-306. 10.1038/d41573-020-00073-5.

12. O'Callaghan KP, Blatz AM, Offit PA. Developing a SARS-CoV-2 vaccine at warp speed. JAMA. 2020;324(5):437-438. https://doi. org/10.1001/jama.2020.12190

13. Hosangadi D, Warmbrod KL, Martin EK, et al. Enabling emergency mass vaccination: innovations in manufacturing and administration during a pandemic. Vaccine. 2020;38(26):4167-4169. https://doi. org/10.1016/j.vaccine.2020.04.037

14. Hamel L, Kirzinger A, Munana C, Brodie M. Kaiser Family Foundation. KFF COVID-19 vaccine monitor: December 2020. Accessed Jan 4, 2021. https://www.kff.org/coronavirus-covid-19/report/kff-covid19-vaccine-monitor-december-2020/

15. Dubé E, Laberge $C$, Guay $M$, Bramadat $P$, Roy R, Bettinger J. Vaccine hesitancy: an overview. Hum Vaccin Immunother. 2013;9(8): 1763-1773. https://doi.org/10.4161/hv.24657

16. DeRoo SS, Pudalov NJ, Fu LY. Planning for a COVID-19 Vaccination Program. JAMA. 2020;323(24):2458-2459. https://doi.org/-10.1001/ jama.2020.8711

17. Total Number of Medicare Beneficiaries. Kaiser Family Foundation. Published Mar 12, 2019. Accessed Jun 10, 2020. https://www.kff. $\mathrm{org} /$ medicare/state-indicator/total-medicare-beneficiaries/
18. Centers for Disease Control and Prevention. People who are at higher risk for severe illness. Published Jun 25, 2020. Accessed Jul 13, 2020. https://stacks.cdc.gov/view/cdc/86074

19. Oppel RA, Gebeloff R, Lai KKR, Wright W, Smith M. The fullest look yet at the racial inequity of coronavirus. New York Times. Published Jul 5, 2020. Accessed Jul 13, 2020. https://www.nytimes.com/ interactive/2020/07/05/us/coronavirus-latinos-african-americans-cdcdata.html

20. Garg S, Kim L, Whitaker M, et al. Hospitalization rates and characteristics of patients hospitalized with laboratory-confirmed coronavirus disease 2019 - COVID-NET, 14 states, March 1-30, 2020. MMWR Morb Mortal Wkly Rep. 2020;69(15):458-464. 10.15585/mmwr.mm6915e3.

21. Centers for Disease Control and Prevention. National Center for Health Statistics. Early release of selected estimates based on data from the 2018 National Health Interview Survey, Figure 5.3. Published May 29, 2019. Accessed Jun 10, 2020. https://www.cdc.gov/ nchs/nhis/releases/released201905.htm

22. Poteat T, Millett GA, Nelson LE, Beyrer C. Understanding COVID-19 risks and vulnerabilities among black communities in America: the lethal force of syndemics. Ann Epidemiol. 2020;47:1-3. 10.1016/ j.annepidem.2020.05.004.

23. Grohskopf LA, Liburd LC, Redfield RR. Addressing influenza vaccination disparities during the COVID-19 pandemic. JAMA. 2020;324(11): 1029-1030. 10.1001/jama.2020.15845

\section{Get the Annals of \\ FAMILY MEDICINE} Family Medicine by E-mail

Make sure you see every new issue

while it's fresh; have the table of

contents sent to you by e-mail for

easy access to articles of interest.

Don't miss important research.

Request the e-mail table of contents at https://www.annfammed.org/ JANUARYIFEBRUARY 2021 . Vol 19, No. 1

Editorial | Original Research | Research Briefs । Special Reports । Reflections Innovations I Departments

Our January 2021 issue focuses on Racism and features a joint editorial from the editors of 10 North American primary care journals.

For more open access content, see our Racism in Medicine bibliography and preprint collection.

The full text of the journal is available online at wmw. AnnFamMed.org and through various aggregators, including PubMed Central, EBSCO, and ClinicalKey. The Annals is indexed in the MEDLINE, Science Citation Index Expanded, Current Contents/Clinical Medicine, EMBASE, and CINAHL databases.

\section{EDITORIAL}

Systemic Racism and Health Disparities: A Statement From Editors of Family Medicine Journals Sumi M. Sexton; Caroline R. Richardson; Sarina B. Schrager, Marjorie A. Bowman; John Hickner; Christopher P. Morley; Timothy F. Mott; Nicholas Pimiott; John W. Sauttz; Barry D. Weiss

The Annals and 10 other leading North American primary care joumals pledge to confront the problem of racism in medicine by cultivating content that emphasizes cultural humility diversity \& inclusion, and the effects of implicit bias. As pert of this pledge, this iseve teatures original research articles and persone reflections on the theme of systemic racism and health inequities.

\section{ORIGINAL RESEARCH}

ACD Discrimination and Mesical Mistrust in a Racially and Ethnically Diverse Sample of California Adults Mohsen Bazargan; Sharon Cobb; Shervin Assar

The authors show that discrimination against patients, perceived or actual, is correlated with medical mistrust and that decreasing discrimination may improve trust in medical providers and decrease disparities in health 